\section{Keep an eye on Murphy's eye during percutaneous dilatational tracheostomy}

Sir,

The report by Panigrahi et al. made for interesting reading. ${ }^{[1]}$ We would like to make certain observations regarding such a complication.

The polyvinyl chloride tracheal tube (TT) possesses a preformed contour. When we keep the tube in such a position that the inherent curve of the tube faces anteriorly, the attachment of the pilot balloon also faces anteriorly. In this position, beveled distal end of the tube faces to the left and the Murphy's eye to the right.

When a right-handed anesthesiologist intubates the trachea with this tube, he performs laryngoscopy along the right border of the tongue and fixes the TT at the right corner of the mouth. In general, the TT curve is tilted toward right and the Murphy's eye faces posteriorly in this situation.

Before performing percutaneous dilatational tracheostomy, the TT is withdrawn so that it does not come in the way of the introducer needle. If the TT is withdrawn in the same position as described above, it is extremely unlikely that the guidewire will enter the Murphy's eye without piercing the TT first. If the tube is rotated by $90^{\circ}$ to the left by bringing its inherent curve anteriorly, there is again very little space for the guidewire to enter the Murphy's eye. Only if the TT is further rotated $90^{\circ}$ to the left, the Murphy's eye is exposed to guidewire entry. This position of the TT is not the usual position in which the withdrawn tube is kept by most of the clinicians.

Moreover, if the TT has been initially placed and subsequently withdrawn in such a position that its curve and pilot balloon attachment faced to the left, the Murphy's eye becomes directly exposed to guidewire entry leading to the problems described. Hence, we should be careful during the withdrawal of TT that it should not lie in a position that exposes the Murphy's eye to the path of the introducer needle.

Another way in which the guidewire can enter the Murphy's eye is retrogradely. If the J-tip of the guidewire faces cephalad during insertion, it may move cephalad and enter the Murphy's eye. On looking closely at the two figures, we can conclude that in the second case, the 
guidewire had directly entered the Murphy's eye and not retrogradely.

We are also concerned that during withdrawal of the $\mathrm{TT}$, the guidewire was allowed to come out along with the tube. Loss of a correctly placed guidewire can be catastrophic in certain situations and attempts should be made to retain it in position.

Finally, the introducer needle has no scope to "pierce" the Murphy's eye. All it can do is to "pass" through it!

\section{Financial support and sponsorship}

Nil.

\section{Conflicts of interest}

There are no conflicts of interest.

Prakash K. Dubey, Om P. Sanjeev ${ }^{1}$ Department of Anesthesiology and Critical Care Medicine, Indira Gandhi Institute of Medical Sciences, Patna, Bihar, ${ }^{1}$ Department of Anesthesiology and Critical Care Medicine, Ram Manohar Lohia Institute of Medical Sciences, Lucknow, Uttar Pradesh, India
Correspondence: Prof. Prakash K. Dubey, Department of Anesthesiology and Critical Care Medicine, Indira Gandhi Institute of Medical Sciences Campus, E 3/4, Patna - 800 014, Bihar, India.

E-mail: pkdubey@ hotmail.com

\section{Reference}

1. Panigrahi B, Samaddar DP, Kumar T. Inadvertent migration of guidewire into Murphy's eye of endotracheal tube during percutaneous dilatational tracheostomy. Indian J Crit Care Med 2016;20:188-90.

This is an open access article distributed under the terms of the Creative Commons Attribution-NonCommercial-ShareAlike 3.0 License, which allows others to remix, tweak, and build upon the work non-commercially, as long as the author is credited and the new creations are licensed under the identical terms.

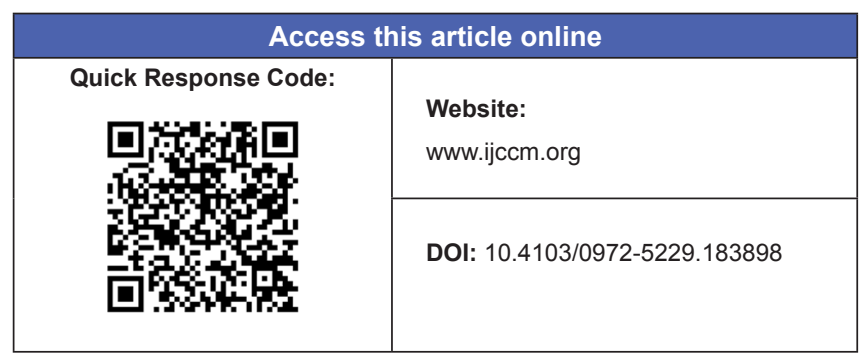

How to cite this article: Dubey PK, Sanjeev OP. Keep an eye on Murphy's eye during percutaneous dilatational tracheostomy. Indian J Crit Care Med 2016;20:379-80. 